\title{
Eğilme Etkisi Altındaki Lifli Betonarme Kirişlerin Doğrusal Olmayan Analizi
}

\author{
${ }^{1}$ Ahmet Hamdi Serdar, ${ }^{2}$ Gamze Demirtaş ${ }^{1}$ Mehmet Sarıbıyık, ve * 1,2 Naci Çağlar \\ ${ }^{1}$ Sakarya Uygulamalı Bilimler Üniversitesi, Teknoloji Fakültesi, İnşaat Mühendisliği Bölümü, Sakarya, Türkiye \\ ${ }^{2}$ Sakarya Üniversitesi, Mühendislik Fakültesi, İnşaat Mühendisliği Bölümü, Sakarya, Türkiye
}

\section{Özet}

Taşıyıcı sistem elemanlarının üretilmesinde lifli betonların kullanılması gün geçtikçe yaygınlaşmaktadır. Lifli betonlar, klasik betonlara göre süneklik, dayanım ve enerji yutma kapasitesi gibi parametreler açısından daha olumlu sonuçlar vermektedir. Bu çalışmada lif katkılı beton ile üretilen betonarme kirişlerin eğilme davranışının sayısal olarak incelenmiştir. Bu amaçla, ABAQUS sonlu elemanlar programı yardımıyla doğrusal olmayan sonlu eleman modeli oluşturulmuş ve modelin doğruluğu literatürden seçilen deneysel çalışmalar ile yapılmıştır. Doğrulanan sonlu eleman modeliyle parametrik bir çalışma gerçekleştirilmiş ve lif katkılı beton ile üretilen betonarme kirişlerin eğilme davranışına çekme donatısı oranındaki değişimin etkisi araştırılmıştır. Elde edilen sonuçlar grafikler halinde sunularak yorumlanmıştır.

Anahtar Kelimeler: Lifli beton, Sonlu eleman analizi, Eğilme davranışı, ABAQUS.

\section{Nonlinear Analysis of Fiber Reinforced Concrete Beams under Bending Effect}

\begin{abstract}
The use of fiber in reinforced concrete structures is becoming widespread recently. Fiber reinforced concretes have more positive affects in terms of parameters such as ductility, strength and energy absorption capacity compared to conventional concretes. In this study, it is aimed to numerically investigate the bending behavior of reinforced concrete beams produced with fiber reinforced concrete. For this purpose, a nonlinear finite element model was created by using of ABAQUS finite element program, and the model was verified by experimental studies selected from the literature. A parametric study was carried out with the verified finite element model and the effect of change in tensile reinforcement ratio on the bending behavior of reinforced concrete beams produced with fiber reinforced concrete was investigated. The obtained results are presented in graphics.
\end{abstract}

Keywords: Fiber reinforced concrete, Finite element analysis, Bending behavior, ABAQUS.

\section{Giriş}

Eğilme etkisine karşın beton ve çeliğin birlikte kullanılması fikri ilk olarak 1850'li yıllarda T. Hyatt tarafından kurgulanmış ve betonarme yapı formu önerilmiştir [1]. Beton içerisine lif ya da tel katılması konusundaki ilk patent 1847 yılında J. Lambot tarafından alınmıştır [1]. Lifli beton; yalın betonun içerisine çeşitli türleri bulunan liflerin rastgele katılmasıyla elde edilmektedir. Geleneksel beton ve lifli beton davranış açısından birbirinden oldukça farklıdır. Klasik beton malzemesinin aksine lifli beton malzemesinde çekme çatlağı oluştuktan sonra gerilmeler, beton matrisine katılan liflerin köprü vazifesi görmesiyle komşu bölgelere aktarılır [2]. Literatürde gerçekleştirilmiş olan

* Sorumlu Yazar

caglar@sakarya.edu.tr; caglar@subu.edu.tr

+902646160010; +902642955729 
hem nümerik hem deneysel çalışmalarda, lifli betonun klasik betona göre yapı davranışına süneklik, dayanım ve enerji yutma kapasitesi açısından önemli katkılar sağladığı belirlenmiştir [26]. Literatürdeki birçok çalışmada, beton matrisine kancalı lif eklenmesinin betonun şekil değiştirmesine katkı sağladığı [3], çelik lif katkılı geleneksel beton kullanılarak üretilen kirişlerin kesme dayanımının tamamen lifli betonun çekme gerilmesine bağlı olduğu tespit edilmiştir [4]. Taşıyıcı sistem elemanlarının birleşim bölgelerinde oluşabilecek çatlaklar karşısında, lifli beton kullanımının etriye kullanımından daha faydalı olduğu ve daha fazla moment taşıyabildiği tespit edilmiştir [5,6].

Deneysel çalışmalar, yapı ve yapı elemanlarının davranışlarının incelenmesinde kullanılabilecek olan en önemli yöntemlerden biridir. Bilgisayar programları ile oluşturulan modeller ise gerçek davranışı simüle ederek, deneysel çalışma yapmadan davranış ile ilgili bilgi sahibi olunmasına imkan tanımaktadır. Nümerik modellerin, gerçek modelleri temsil edebildiğini göstermek için, laboratuvar ortamında deneysel çalışması yapılan elemanların bilgisayar ortamında modellenerek yeterli yaklaşıklıkta sonuç verebildiğinin doğrulanması gerekmektedir. Deneylerden elde edilen sonuçların, analiz sonuçlarıyla uyum içerisinde olması, incelenen yapı elemanlarının performansları hakkında farklı parametreler açısından gözlem yapabilme firsatı tanımaktadır. Böylece deneysel çalışmaya kıyasla hem maliyet, hem de sonuç alabilme süresindeki avantajların yanında, çok daha fazla numune üzerinde analizler gerçekleştirilerek veri çeşitliliği arttır1labilmektedir.

Bu çalışmada lif katkılı beton ile üretilen betonarme kirişlerin eğilme davranışına çekme donatısı oranındaki değişimin etkisi nümerik olarak incelenmiştir. Bu amaçla, ABAQUS sonlu elemanlar programı yardımıyla doğrusal olmayan analizler gerçekleştirilmiştir. Çalışmanın ilk aşamasında literatürden seçilen deneysel sonuçlar ile sonlu eleman modelinin doğrulanması yapılmıştır. Çalışmanın ikinci aşamasında ise doğrulanan sonlu eleman modeliyle parametrik bir çalışma gerçekleştirilmiştir.

\section{Deneysel Çalışma}

Literatürden seçilen deneysel çalışma [7] sonuçları kullanılarak sonlu eleman modelinin doğrulanması yapılmıştır. Ulzurrun ve Zanuy [7] tarafından gerçekleştirilen deneysel çalışmada kiriş numunesi $2 \mathrm{~m}$ açıklığında 125x250 mm dikdörtgen kesite sahiptir. Basınç ve çekme bölgesinde $16 \mathrm{~mm}$ çapında 2 adet nervürlü donatı yerleştirilmiştir. Kirişlerde etriye bulunmamakta, kesme etkisi beton matrisinde bulunan çelik lifler ile karşılanmaktadır ve şematik gösterimi Şekil 1'de verilmiştir. Numuneler 3 noktalı eğilme deneyi yapılmış ve net açıklı $1.6 \mathrm{~m}$ olarak belirlenmiştir. Sonlu eleman modelleri oluşturulan $\mathrm{C}$ ve $\mathrm{F}$ serisine ait numunenin malzeme özellikleri ise Tablo 1'de verilmiştir. Deneysel çalışmada $\mathrm{C}$ numunesi \% $0.50 \mathrm{~F}$ numunesi ise \% 1.00 oranında çelik lif oranına sahiptir. Deneysel çalışmada numunelere statik testler, $0.1 \mathrm{~mm} / \mathrm{s}$ hızında piston kontrolü ile orta açıklıkta bir yük uygulanarak gerçekleştirilmiştir. 


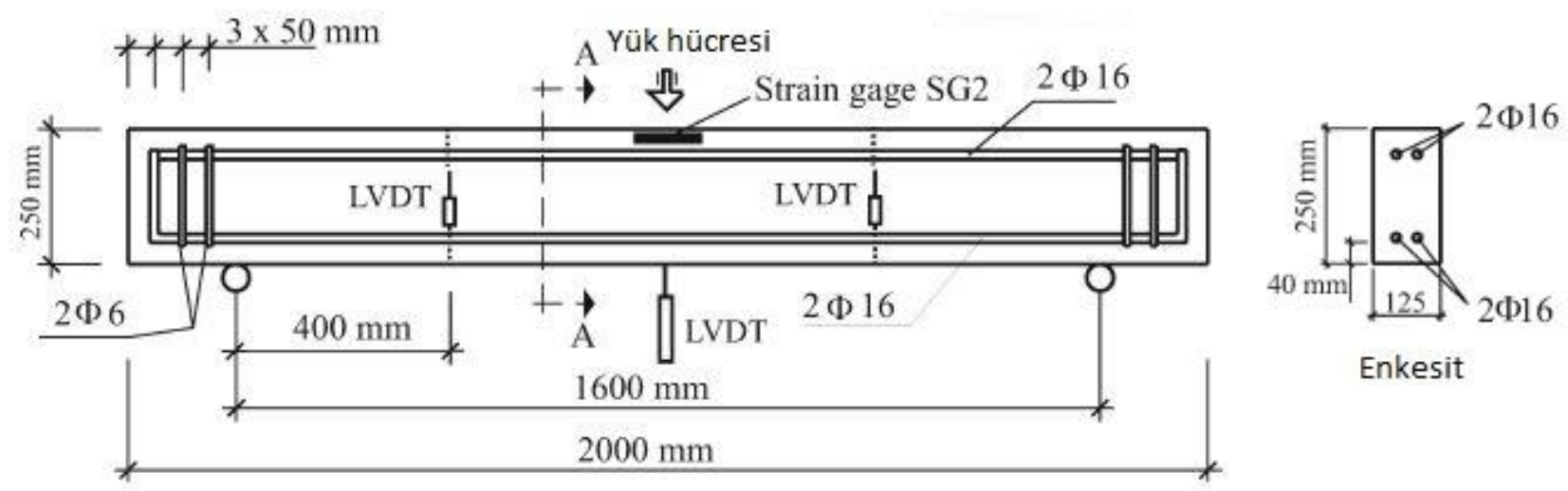

Şekil 1. Kiriş geometri ve en kesiti [7]

Tablo 1. Beton malzeme özellikleri [7]

\begin{tabular}{|c|c|c|c|c|c|c|c|}
\hline Seri & $\begin{array}{l}\text { Lif oranı } \\
(\%)\end{array}$ & Lif tipi & $\begin{array}{l}\text { Lif uzunluğu/ } \\
\text { Lif çapı (mm) }\end{array}$ & $\begin{array}{l}\text { Lif akma } \\
\text { dayanımı (MPa) }\end{array}$ & $\begin{array}{l}\text { Basınç dayanımı } \\
(\mathrm{MPa})\end{array}$ & $\begin{array}{l}\text { Dolaylı çekme } \\
\text { dayanımı(MPa) }\end{array}$ & $\begin{array}{l}\text { Kırılma } \\
\text { enerjisi } \\
(\mathrm{kN} / \mathrm{m})\end{array}$ \\
\hline$C$ & 0.5 & Kancal 1 & $60 / 0.75$ & 1200 & 61.4 & 6.7 & 6.75 \\
\hline$F$ & 1 & Kancalı & $60 / 0.75$ & 1200 & 61.3 & 6.8 & 9.04 \\
\hline
\end{tabular}

\section{Sonlu Eleman Modeli}

Betonarme kirişlerin doğrusal olmayan analizleri ABQUS sonlu eleman programı ile gerçekleştirilmiştir. Beton 3 boyutlu katı eleman (solid), donatı ise çubuk elemanlar (truss) olarak modellenmiştir. Beton modelinin oluşturulmasında; 3 yer değiştirme serbestlik dereceli, 8-düğüm ve azaltılmış integrasyon noktalı (C3D8R) sonlu elemanlar kullanılmıştır. Donatı elemanları ise eksenel doğrultuda tek serbestlik dereceli, 2-düğüm noktalı, lineer doğrusal (T3D2) sonlu eleman parçaları olarak modellenmiştir. Beton ve donatının birlikte çalışabilmesi için aralarındaki etkileşim, ortak serbestlik derecesi ile hareketi sağlayan gömülü (embedded) özelliği ile sağlanmıştır.

Yapılan analizlerde statik yükleme deney koşullarına uygun şekilde kiriş orta noktasında çizgisel, yerdeğiştirme kontrollü olarak uygulanmıştır. Mesnetler deney düzeneğindeki konumları dikkate alınarak çizgisel olarak tanımlanmış ve sistem basit mesnetli olarak modellenmiştir. Analiz hassasiyetini arttırmak için yapılan çalışmalar ile optimum mesh boyutu $50 \mathrm{~mm}$ olarak belirlenmiştir.

Donatı malzeme modelini oluşturmak için elastoplastik malzeme modeli kullanılmıştır. Deneysel çalışmada boyuna donatı B500SD özelliklerinde olduğu belirtildiği için akma gerilmesi $500 \mathrm{MPa}$, kopma gerilmesi $575 \mathrm{MPa}$ olarak dikkate alınmıştır. Çelik lifle güçlendirilmiş betonun doğrusal olmayan basınç gerilmesi-birim şekil değiştirme ilişkisini modellemek için Dhakal ve diğ. [8] tarafından önerilen model kullanılmıştır: 


$$
\begin{aligned}
& \sigma_{\mathrm{c}}=\mathrm{f}_{\mathrm{c}}\left[\frac{\left(\varepsilon / \varepsilon_{\text {peak }}\right)}{1-\left(\varepsilon / \varepsilon_{\text {peak }}\right)+\left(\varepsilon / \varepsilon_{\text {peak }}\right)^{2}}\right] \\
& \varepsilon_{\text {peak }}=\varepsilon_{0}\left(1+2000 x a_{e} x V_{f}^{2}\right)
\end{aligned}
$$

Burada; $\mathrm{f}_{\mathrm{c}}$ çelik lifli betonun basınç dayanımını, $\varepsilon_{0}$ yalın beton için maksimum gerilmeye karşılık gelen birim şekil değiştirmeyi, $\varepsilon_{\text {peak }}$ çelik lifli beton için maksimum gerilmeye karşılık gelen birim şekil değiştirmeyi $a_{e}$ lifin özelliğini dikkate alan deneysel bir sabiti ve $V_{\mathrm{f}}$ hacimsel lif oranını ifade etmektedir. Betonun çekme modeli, deneysel çalışmadan elde edilmiş olan kırılma enerjisi ile programa tanımlanmıştır.

\section{Sonlu Eleman Modelinin Doğrulanması}

Sonlu eleman modelinin doğrulanması, literatürden seçilen deneysel çalışma [7] ile yapılmıştır. Sonlu eleman modeli analizleri ve deneysel çalışmada elde edilen yük-deplasman eğrileri Şekil 2a ve 2 b'de gösterilmektedir. Ayrıca, deneysel çalışma sonucunda raporlanan çatlak gelişimleri ile analiz sonucunda numunelerde oluşan çatlak dağılımları Şekil 3'de verilmektedir.

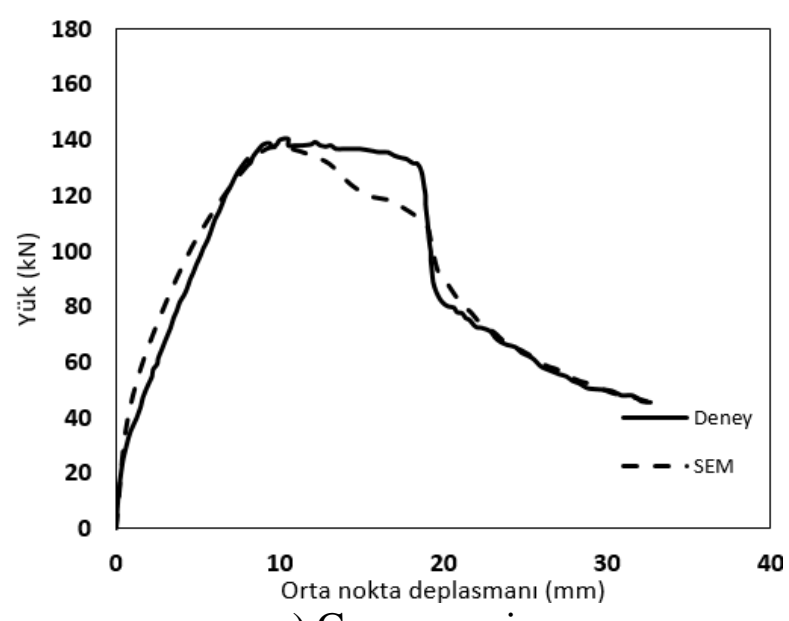

a) $\mathrm{C}$ numunesi

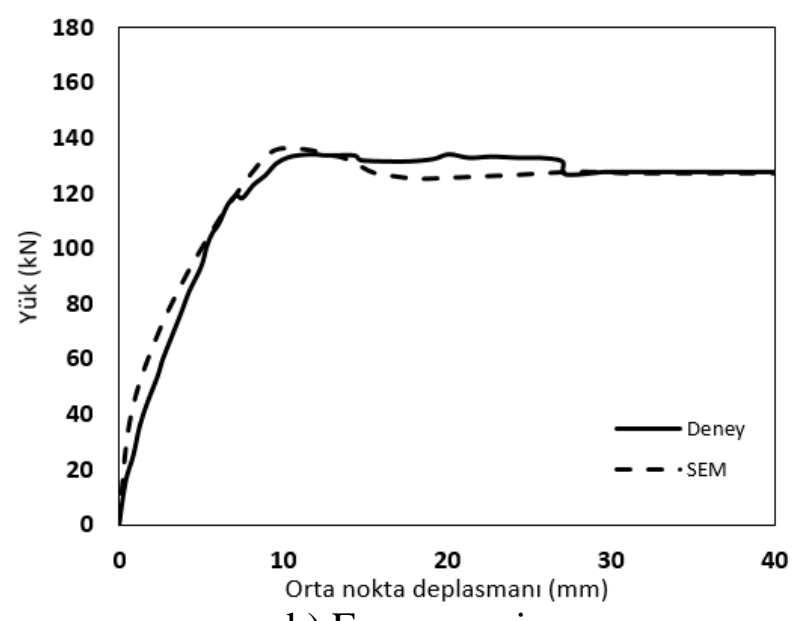

b) F numunesi

Şekil 2. Sonlu eleman modeli sonuçları ile deney sonuçlarını karşılaştırılması

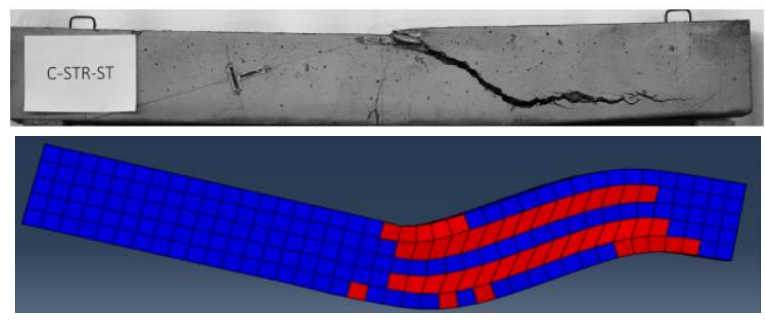

a) C numunesi

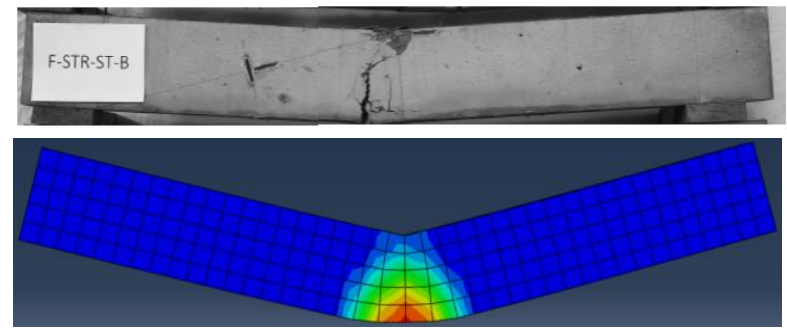

b)F numunesi

Şekil 3. Statik deney sonrası kiriş numunelerinin çatlak dağılımı 
Şekil 2 ve 3'den görüldüğü gibi, sonlu eleman analiz sonuçları ile deney sonuçları birbiri ile oldukça uyumludur. Maksimum yük taşıma kapasiteleri; C numunesi için, deney sonucunda 141 $\mathrm{kN}$ analiz sonucunda $138 \mathrm{kN}$, F numunesi için, deney sonucunda $135 \mathrm{kN}$ analiz sonucunda $137 \mathrm{kN}$ olarak belirlenmiştir. Çatlak dağılımlarının ise birbiri ile uyumlu olduğu, C numunesinde sağ mesnet bölgesinde kesme çatlağı oluşurken, F numunesinde eğilme çatlakları olduğu gözlemlenmiştir. Dolayısıyla bu çalışma kapsamında oluşturulan sonlu eleman modeli, lifli beton ile üretilen betonarme kirişlerin eğilme etkisi altındaki gerçek davranışını deneysel çalışmalara oranla daha kolay ve başarılı bir şekilde simüle edebileceği ortaya çıkmıştır.

\section{Parametrik Çalışma}

Lifli beton ile üretilen betonarme kirişlerin eğilme etkisi altındaki davranışına boyuna donatı oranının etkisini incelemek amacıyla doğrulaması yapılan sonlu eleman modeli yardımıyla parametrik bir çalışma gerçekleştirilmiştir. Farklı donatı oranlarına bağlı olarak nümerik analizleri gerçekleştirilen betonarme kirişler Tablo 2'de verilmiştir.

Tablo 2. Parametrik çalışma verileri

\begin{tabular}{|c|c|c|c|c|c|c|}
\hline \multicolumn{2}{|c|}{ Seri } & $\begin{array}{l}\text { Lif oranı } \\
\text { (\%) }\end{array}$ & $\begin{array}{c}\text { Basınç } \\
\text { dayanımı } \\
(\text { MPa })\end{array}$ & $\begin{array}{c}\text { Çekme } \\
\text { Donatısı }\end{array}$ & $\rho$ & Uygulama \\
\hline \multirow{6}{*}{$\mathrm{C}$} & $\mathrm{C} 1$ & \multirow{6}{*}{0.50} & \multirow{6}{*}{61.4} & $2 \phi 12$ & 0.00724 & Sayısal \\
\hline & $\mathrm{C} 2$ & & & $2 \phi 14$ & 0.00985 & Sayısal \\
\hline & $\mathrm{C} 3$ & & & $2 \phi 16$ & 0.01287 & Deney \\
\hline & $\mathrm{C} 4$ & & & $2 \phi 18$ & 0.01629 & Sayısal \\
\hline & $\mathrm{C} 5$ & & & $2 \phi 20$ & 0.02011 & Sayısal \\
\hline & C6 & & & $2 \phi 22$ & 0.02433 & Sayısal \\
\hline \multirow{6}{*}{$\mathrm{F}$} & F1 & \multirow{6}{*}{1.00} & \multirow{6}{*}{61.3} & $2 \phi 12$ & 0.00724 & Sayısal \\
\hline & $\mathrm{F} 2$ & & & $2 \phi 14$ & 0.00985 & Sayısal \\
\hline & F3 & & & $2 \phi 16$ & 0.01287 & Deney \\
\hline & F4 & & & $2 \phi 18$ & 0.01629 & Sayısal \\
\hline & F5 & & & $2 \phi 20$ & 0.02011 & Sayısal \\
\hline & F6 & & & $2 \phi 22$ & 0.02433 & Sayısal \\
\hline
\end{tabular}

Analiz sonuçları incelendiğinde, klasik beton malzemesi ile üretilen betonarme kirişlerde olduğu gibi donatı oranının minimum donatı oranına yaklaşması durumunda sünek davranış gösterirken maksimum donatı oranına yaklaşması durumunda ise gevrek bir davranış göstermektedir. Donatı oranının artması ile betonarme kirişlerin yük taşıma kapasitesinde artış gözlemlenmekle birlikte davranış daha gevrek hale gelmektedir (Şekil 4).

Lif oranının \% 0.50 olduğu C serisinde düşük donatı oranlarında sünek davranış gösterirken donatı oranı \%1.00 değerinin üzerine çıkmasından sonra kiriş gevrek davranış göstermekte ve çekme donatısının akması sonrasında aniden göçmektedir. Lif oranının \% 1.00 olduğu F serisinde ise donatı oranı $\% 1.50$ değerinin üzerine çıkmasından sonra kiriş gevrek davranış göstermektedir. 

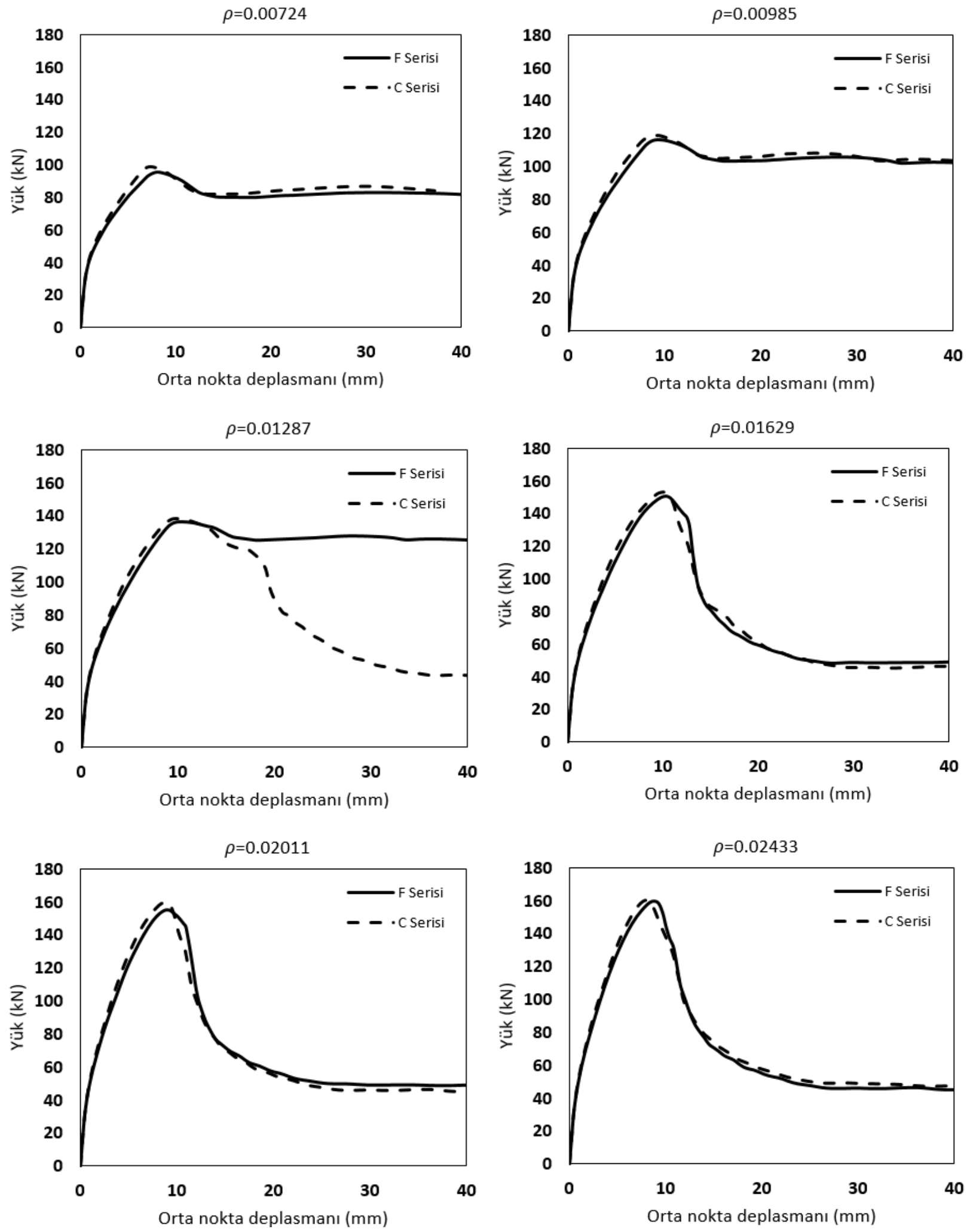

Şekil 4. Donatı oranına bağlı yük-deplasman grafikleri 
Lif oranının betonarme kirişin davranışına olan etkisi, donatı oranının $\rho=0.01287$ olduğu kirişlerde daha belirgin olarak gözükmektedir. Analiz sonuçlarından da görüldüğü gibi donatı oranının $\rho=0.01287$ civarında olduğu kirişlerde lif oranının artması ile betonarme kirişlerin daha sünek davranış gösterdiği ve enerji yutma kapasitelerinde belirgin bir artış olduğu gözlemlenmektedir. Bununla birlikte boyuna donatının tüm oranlarında lif oranındaki değişisimin maksimum yük taşıma kapasitesine önemli bir etkisi olmadığ gözlemlenmiştir.

\section{Sonuçlar}

Bu çalışmada, lifli beton ile üretilen betonarme kirişlerin davranışları nümerik olarak incelenmiştir. Sonlu eleman modelinin doğrulanması için kullanılan deneysel çalışma sonuçları literatürden seçilmiştir. Nonlineer malzeme modeli kullanılarak oluşturulan sonlu eleman modeli sonuçlarının deneysel sonuca oldukça yakın sonuçlar verdiği ve çatlak gelişimleri açısından benzerlik gösterdiği görülmüştür.

Lifli beton ile üretilen betonarme kirişlerin davranışına boyuna donatının etkisi incelendiğinde donatı oranının artması ile maksimum yük taşıma kapasitesi artarken davranışın gevrekleştiği gözlemlenmiştir. Lif oranının maksimum yük taşıma kapasitesine önemli bir katkısı olmazken, lif oranının artmasıyla enerji yutma kapasitesinin artabildiği görülmüştür.

\section{Kaynaklar}

[1] Kurt G, Lif İçeriği ve Su/Çimento Oranının Fibrobetonun Mekanik Davranışına Etkileri, İstanbul Teknik Üniversitesi, Fen Bilimleri Üniversitesi, YL Tezi, 2006.

[2] Taşdemir M A, Yerlikaya M, Bayramov F, Geleneksel ve Yüksek Performanslı Çelik Donatılı Betonlar, TMH 2003;4:76-84.

[3] Ezeldin A S, Balaguru N P, Normal- and High-Strength Fiber-Reinforced Concrete under Compression, Journal of Materials in Civil Engineering, 1992.

[4] Casanova P, Rossi P, Analysis and Desing of Steel Fiber Reinforced Concrete Beams, Structural Journal, 1997; 94:595-602.

[5] Koç V, Birinci F, Lifli Betonda Boyut Etkisi Tokluk ve Kılrılma Enerjisi, SDU International Thecnologic Science, 2012; 4:24-40.

[6] Tokgöz S, Tests on Plain and Steel Fiber Concrete-Filled Stainless Stell Tubular Columns, Journal of Constructional Steel Research, 2015; 129-135.

[7] Zanuy C, Ulzurrun G S, Residual behavior of reinforced steel fiber-reinforced concrete beams damaged by impact. Structural Concrete, 2019; 20(2): 597-613.

[8] Dhakal R P, Wang C, Mander J B, Behavior of steel fibre reinforced concrete in compression, 2005. 